\title{
Bicarbonate enhances expression of the endocarditis and biofilm associated pilus locus, ebpR-ebpABC, in Enterococcus faecalis
}

Agathe Bourgogne ${ }^{1,2}, \mathrm{~L}$ Charlene Thomson ${ }^{1,2}$, Barbara E Murray ${ }^{1,2,3^{*}}$

\begin{abstract}
Background: We previously identified ebpR, encoding a potential member of the AtxA/Mga transcriptional regulator family, and showed that it is important for transcriptional activation of the Enterococcus faecalis endocarditis and biofilm associated pilus operon, ebpABC. Although ebpR is not absolutely essential for ebpABC expression (100-fold reduction), its deletion led to phenotypes similar to those of an ebpABC mutant such as absence of pili at the cell surface and, consequently, reduced biofilm formation. A non-piliated ebpABC mutant has been shown to be attenuated in a rat model of endocarditis and in a murine urinary tract infection model, indicating an important participation of the ebpR-ebpABC locus in virulence. However, there is no report relating to the environmental conditions that affect expression of the ebpR-ebpABC locus.

Results: In this study, we examined the effect of $\mathrm{CO}_{2} / \mathrm{HCO}_{3}{ }^{-}, \mathrm{pH}$, and the Fsr system on the ebpR-ebpABC locus expression. The presence of 5\% $\mathrm{CO}_{2} / 0.1 \mathrm{M} \mathrm{HCO}^{-}{ }^{-}$increased ebpR-ebpABC expression, while the Fsr system was confirmed to be a weak repressor of this locus. The mechanism by which the Fsr system repressed the ebpRebpABC locus expression appears independent of the effects of $\mathrm{CO}_{2}{ }^{-}$bicarbonate. Furthermore, by using an ebpA:: lacZ fusion as a reporter, we showed that addition of $0.1 \mathrm{M}$ sodium bicarbonate to TSBG (buffered at pH 7.5), but not the presence of $5 \% \mathrm{CO}_{2}$, induced ebpA expression in TSBG broth. In addition, using microarray analysis, we found 73 genes affected by the presence of sodium bicarbonate (abs(fold) $>2, P<0.05$ ), the majority of which belong to the PTS system and ABC transporter families. Finally, pilus production correlated with ebpA mRNA levels under the conditions tested.

Conclusions: This study reports that the ebp locus expression is enhanced by the presence of bicarbonate with a consequential increase in the number of cells producing pili. Although the molecular basis of the bicarbonate effect remains unclear, the pathway is independent of the Fsr system. In conclusion, E. faecalis joins the growing family of pathogens that regulates virulence gene expression in response to bicarbonate and/or $\mathrm{CO}_{2}$.
\end{abstract}

\section{Background}

Enterococci are part of the normal flora in human intestines and are also a leading cause of nosocomial infections [1,2]. These organisms are somehow able to migrate from the gastrointestinal tract into the bloodstream and cause systemic infections such as bacteremia and even endocarditis [2-4]. Although many strains of enterococci seem to be harmless commensals, particular subgroups of Enterococcus faecalis and Enterococcus faecium predominate among isolates from nosocomial

\footnotetext{
*Correspondence: barbara.e.murray@uth.tmc.edu

'Division of Infectious Diseases, Department of Medicine, University of Texas Medical School, (6431 Fannin) Houston, Texas (77030), USA
}

enterococcal infections. In E. faecalis, numerous factors important for virulence have been characterized. For example, the Fsr system, a homologue of the staphylococcal Agr system, has been shown to be important for virulence due, at least in part, to its control of gelatinase and a serine protease expression via a quorum-sensing mechanism [5-7]. Microarray studies also indicated that the Fsr system regulates other genes important for virulence [8], one of which is the locus encoding Ebp pili [8], whose subunits are encoded by the $e b p$ operon [9]. A non-piliated $e b p$ mutant, producing much less biofilm than the parent strain, was shown to be attenuated in a rat model of endocarditis [9] and in a murine urinary
C Biomed Central

(c) 2010 Bourgogne et al; licensee BioMed Central Ltd. This is an Open Access article distributed under the terms of the Creative Commons Attribution License (http://creativecommons.org/licenses/by/2.0), which permits unrestricted use, distribution, and reproduction in any medium, provided the original work is properly cited. 
tract infection model [10]. We previously described EbpR as an important activator of the ebpABC operon encoding the pili in E. faecalis OG1RF [11]. Although $e b p R$ is not essential for $e b p A B C$ expression, we detected 100-fold less $e b p A B C$ mRNA in a $\triangle e b p R$ mutant compared to the OG1RF parent strain. In addition, even in the presence of an intact $e b p R$ gene, only $5-20 \%$ of the cells, grown aerobically in BHI or in TSBG, were found to produce pili (detected by electron microscopy or immunofluorescence) $[9,11]$. These results imply that other regulatory and/or environmental factors may affect pilus production.

Bicarbonate is a major element of the mammalian body for reaching and maintaining homeostasis. In equilibrium with $\mathrm{CO}_{2}, \mathrm{H}_{2} \mathrm{CO}_{2}$ and $\mathrm{CO}_{3}{ }^{2-}$, depending on $\mathrm{pH}$, temperature, and $\mathrm{CO}_{2}$ pressure, bicarbonate does not diffuse freely across the membrane and needs specific transporters [12]. In the stomach, $\mathrm{HCO}_{3}{ }^{-}$is secreted by the surface mucus cells, where it gets trapped in the mucus and forms part of the mucus- $\mathrm{HCO}_{3}{ }^{-}$barrier, thereby maintaining a $\mathrm{pH}$ gradient of $\mathrm{pH} 2$ in the lumen to $\mathrm{pH} 7$ at the mucosal epithelium interface. Interestingly, some microbial pathogens have been shown to respond in vivo to $\mathrm{CO}_{2}$ (from 5 to $20 \%$ ) and/or $\mathrm{HCO}_{3}{ }^{-}$ (10-100 $\mathrm{mM})$ by enhancing production of factors important for virulence (Staphyloccocus aureus [13], Vibrio cholerae [14], group A streptococcus [15], Bacillus anthracis [16,17], Cryptococcus neoformans [18] and Citrobacter rodentium [19]). Regulatory proteins have been described which mediate the $\mathrm{CO}_{2} / \mathrm{HCO}_{3}{ }^{-}$response at the transcriptional level in $B$. anthracis (AtxA-like proteins [20]), in Group A streptococci (Mga [21]) and, recently, in C. rodentium with RegA [19]. For E. faecalis, except for a report showing an increase in cytolysin expression when grown in $80 \% \mathrm{H}_{2}-20 \% \mathrm{CO}_{2}$ [22], we could find no other report of a $\mathrm{CO}_{2} / \mathrm{HCO}_{3}{ }^{-}$effect on known virulence-associated genes. A candidate for such study is the $e b p A B C$ operon and its regulator, $e b p R$, a gene encoding a transcriptional regulator affiliated with the AtxA/Mga family; as mentioned above, this family is known to have its regulon activated in response to elevated $\mathrm{CO}_{2}[15,23]$.

In the present study, we report the identification of environmental conditions affecting the expression of the $e b p R-e b p A B C$ locus and, consequently, pilus production. In addition, we found that Fsr repressed the $e b p R$ $e b p A B C$ locus in all conditions tested, independent of the $\mathrm{CO}_{2}$ /bicarbonate effect. Finally, among the dozens of genes that are differentially expressed after being exposed to bicarbonate, the majority belong to the PTS system and $\mathrm{ABC}$ transporter families.

\section{Results}

$e b p R$ and $e b p A$ expression profiles when grown aerobically in TSBG

We previously identified an E. faecalis transcriptional regulator, EbpR, which positively affects the expression of the endocarditis and biofilm-associated pilus operon, $e b p A B C$ [11]. To further explore $e b p R$ and $e b p A B C$ expression profiles, we created $l a c Z$ fusions with the $e b p R$ and $e b p A$ promoters $\left(\mathrm{P}_{e b p R}:: l a c Z\right.$ and $\left.\mathrm{P}_{e b p A}:: l a c Z\right)$. We first tested the time course of expression of $e b p R$ and $e b p A$ in OG1RF grown aerobically in TSBG (our standard biofilm medium) from mid-log growth phase to late stationary. In these conditions, each fusion showed the same general dome-shape pattern that reached a peak between 5 and 6 hr (Fig. 1A); specifically, the $\beta$-gal units for OG1RF carrying the $e b p A$ promoter were $2.4,5.4$, and 0.4 at mid-log ( $3 \mathrm{hr}$ after starting the culture), entry into stationary ( $5 \mathrm{hr}$ ) and late stationary growth phase $(24 \mathrm{hr})$, respectively, while the $e b p R$ fusion generated consistently lower $\beta$-gal units than the $e b p A$ fusion.

Since $\beta$-galactosidase assays reflect translation as well as transcription, we also directly explored the steadystate mRNA levels of transcripts of $e b p R$ and $e b p A$ with qRT-PCR in the same conditions used above (TSBG, aerobically) compared to the housekeeping gene gyrB. At the peak of $e b p R$ expression, which occurred between mid- and late log phase growth, the ratio between $e b p R$ and $\operatorname{gyr} B$ transcript levels was 0.04 (Fig. 1B). After entry into stationary phase, ebpR expression decreased to an $e b p R / g y r B$ ratio of 0.004 representing a 10 -fold decrease when compared to late log growth phase levels. Likewise, $e b p A$ expression also peaked at the late log growth phase with an $e b p A / g y r B$ ratio of 1.5 and decreased to a ratio $e b p A / g y r B$ of 0.12 (also a 10 -fold reduction when compared to $e b p A$ expression level at late log growth phase). The $e b p A$ steady-state mRNA levels were an average of 37-fold higher than $e b p R$ steady-state mRNA levels. Overall, the patterns between qRT-PCR and the $\beta$-gal assays were similar except for a one-hour delay for peak expression in the $\beta$-gal assays, probably due to a delay between transcription and translation.

The $\mathrm{CO}_{2}-\mathrm{NaHCO}_{3}$ induction effect on ebpR and ebpA expression

As we previously noted [11], EbpR shares some homology with transcriptional regulators of the AtxA/Mga family. In this family, it has been shown that AtxA and Mga activate their regulon from mid-log to entry into stationary phase and that their regulon is affected by the presence of $5 \% \mathrm{CO}_{2} / 0.1 \mathrm{M} \mathrm{NaHCO}_{3}[15,23]$. We therefore tested the effect of $\mathrm{CO}_{2} / \mathrm{NaHCO}_{3}$ on $e b p R$ and 


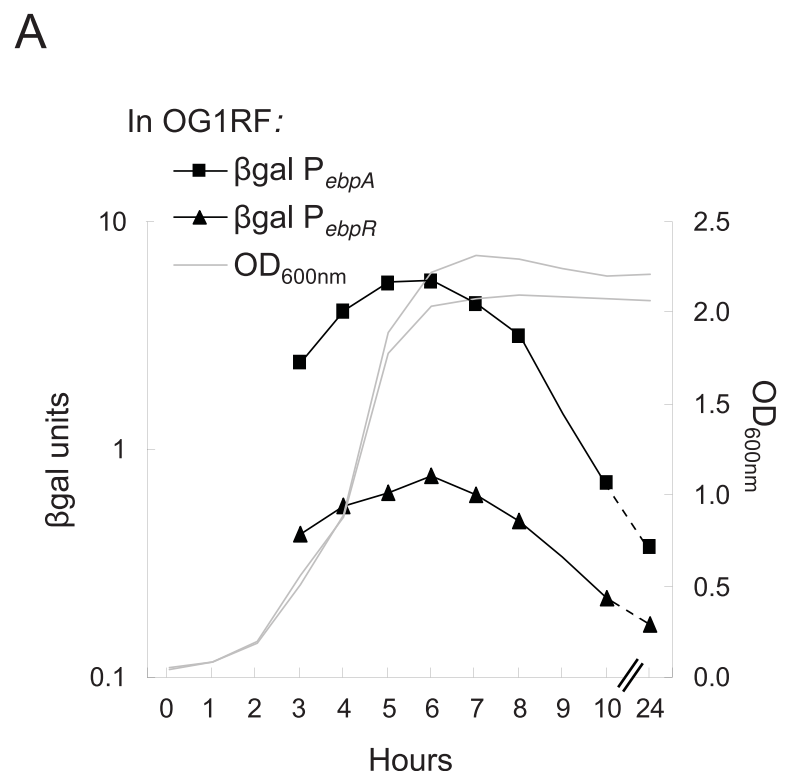

\section{B}

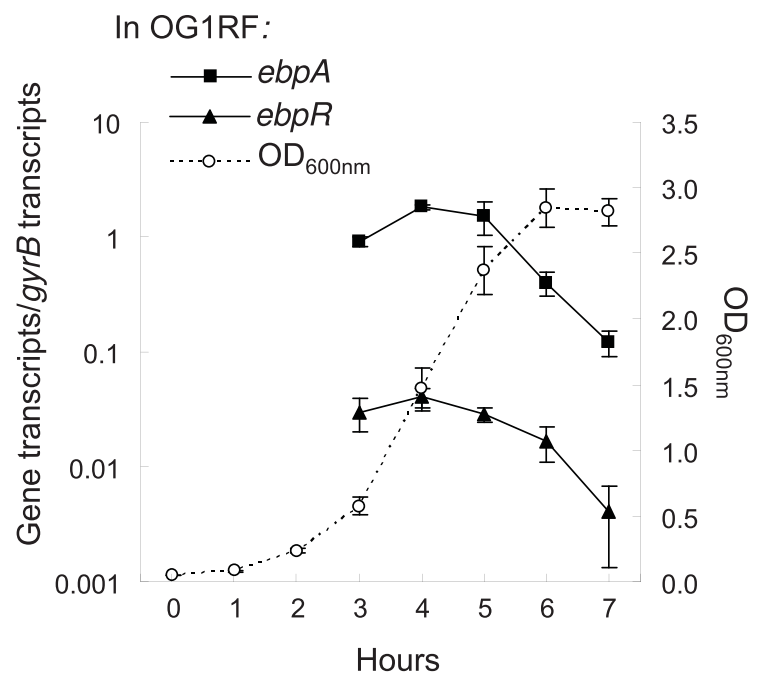

Figure $1 \boldsymbol{e b p R}$ and $\boldsymbol{e b p A}$ expression profiles in OG1RF. A. Expression levels of ebpA and ebpR using gene promoter::/acZ fusions. OG1RF

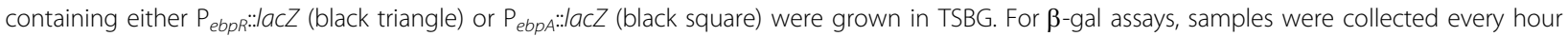
from 3 to $8 \mathrm{hr}$, then at 10 and $24 \mathrm{hr}$ after starting the culture ( $\mathrm{x}$ axis). The left axis represents the $\beta$-gal units $\left(\mathrm{OD}_{420} \mathrm{~nm} / \mathrm{protein}\right.$ concentration in $\mathrm{mg} / \mathrm{ml}$ ). The right axis indicates the $\mathrm{OD}_{600} \mathrm{~nm}$ readings. All sets of cultures presented were analyzed concurrently. This figure is a representative of at least three independent experiments. B. qRT-PCR with RNA purified from OG1RF cultures grown aerobically in TSBG. The left axis represents the level of transcript normalized to gyrB transcript level. The right axis indicates the $\mathrm{OD}_{600 \mathrm{~nm}}$ readings. The dashed line shows the mean (with standard deviation) of 5 independent cultures of OG1RF grown in TSBG. The transcript levels of ebpR (black triangle) and ebpA (black square) shown represent two different data sets, each tested in duplicate that were normalized using gyrB transcript levels.

ebpA expression during growth using the $\mathrm{P}_{e b p R}::$ and $\mathrm{P}_{e b p A}:$ :lacZ fusions in OG1RF as shown in Fig. 2A. For the aerobic cultures, both $e b p R$ and $e b p A \beta$-gal profiles followed the dome-shaped pattern over time, as described above. However, the presence of $\mathrm{CO}_{2} /$ $\mathrm{NaHCO}_{3}$ led to a 2-3 fold increase in the $\beta$-gal units early during growth and, after the cultures entered stationary phase, ebpR and ebpA expression levels continued to increase for two hours and then showed only a slight decrease from $8 \mathrm{hr}$ to $24 \mathrm{hr}$. At $24 \mathrm{hr}$, the $\beta$-gal units for OG1RF carrying the $e b p A$ promoter were 13.9 in the presence of $\mathrm{CO}_{2} / \mathrm{NaHCO}_{3}$ compared to 0.4 aerobically, a 33-fold difference. Similarly, the $\beta$-gal units for OG1RF carrying the $e b p R$ promoter were 1.2 in presence of $\mathrm{CO}_{2} / \mathrm{NaHCO}_{3}$ compared to 0.13 aerobically, a 9-fold difference.

To determine whether the $\mathrm{CO}_{2} / \mathrm{NaHCO}_{3}$ effect on $e b p A$ expression was dependent on the presence of $e b p R$, we tested $e b p A$ expression in an $e b p R$ deletion mutant (TX5514). Using the $e b p R$ deletion mutant (TX5514) containing $\mathrm{P}_{\text {ebp }}$ ::lac $Z$, $\beta$-gal production was assessed in air and in the presence of $5 \% \mathrm{CO}_{2} / 0.1 \mathrm{M}$ $\mathrm{NaHCO}_{3}$ and $\beta$-gal production remained at the background level in both conditions (Fig. 2B). These results combined with our previously published results [11] indicate that, in air as well as in the presence of $5 \%$
$\mathrm{CO}_{2} / 0.1 \mathrm{M} \mathrm{NaHCO}$, ebpR is important for ebpA expression and that the $5 \% \mathrm{CO}_{2} / 0.1 \mathrm{M} \mathrm{NaHCO}_{3}$ effect on ebpA expression level also requires the presence of $e b p R$.

We previously reported that only a fraction of the OG1RF cells were positive for pilus expression by immunofluorescence ([11]). To examine whether the presence of $\mathrm{CO}_{2} / \mathrm{NaHCO}_{3}$ affected the amount of pili per cell or the percentage of cells positive for pilus production, we used flow cytometry. As early as entry into stationary growth phase, a difference in the percentage of pilus positive cell was visible (Fig. 3A) with $53 \%$ positive when grown in air compared to $87 \%$ positive when grown in the presence of $\mathrm{CO}_{2} / \mathrm{NaHCO}_{3}$. The difference in the percentage of positive cells remained in later stages of growth. Specifically, Fig. 3B shows that, at 6 hr, $76 \%$ of the cells were positive when grown in air compared to $99 \%$ when the cells were grown in the presence of $\mathrm{CO}_{2} / \mathrm{NaHCO}_{3}$. The mean fluorescence intensity, between growth conditions and growth phases, remained constant with an average of 268 . We also used anti-EbpC antibodies to probe mutanolysin extracts spotted on a dot blot for pilus production. An approximately four-fold increased signal density was observed in cells grown in the presence of $\mathrm{CO}_{2} / \mathrm{NaHCO}_{3}$ compared to the cells grown in air (Fig. 3C). Additionally, 


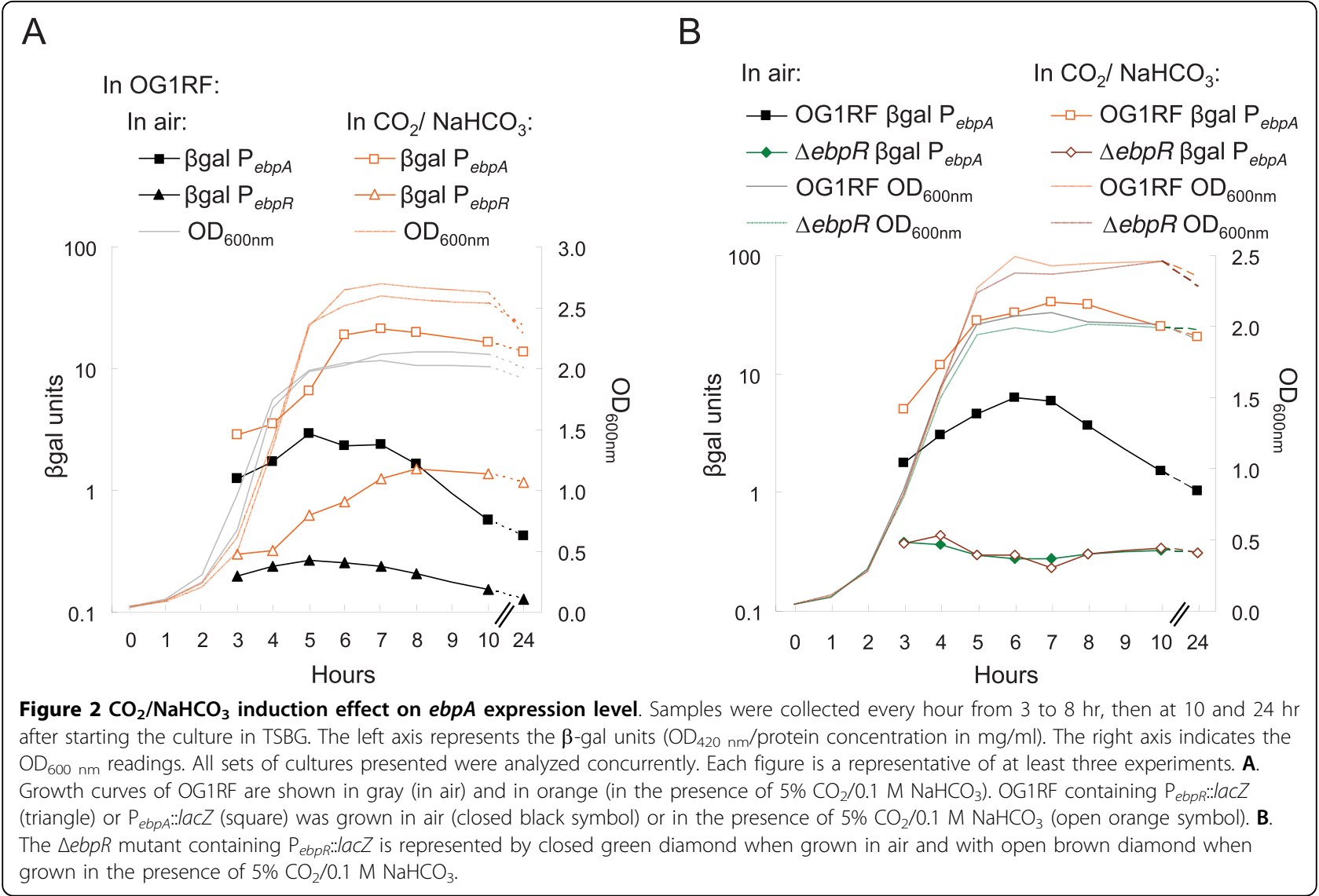

no signal was detectable under either growth condition in the mutant lacking $e b p R$, confirming the importance of $e b p R$ for $e b p A B C$ expression and pilus production aerobically as well as in the presence of $5 \% \mathrm{CO}_{2} / 0.1 \mathrm{M}$ $\mathrm{NaHCO}_{3}$.

\section{The Fsr system effect on the ebp locus}

We previously presented data in our microarray study suggesting that Fsr repressed the ebpR-ebpABC locus. However, the Fsr effect was only seen at one time point (during late log growth phase) using BHI grown cells [8]; in this medium, $f s r B$ expression increased from mid$\log$ to entry into stationary phase and then decreased rapidly [6]. Since our current study used mainly TSBG (our biofilm medium) as growth medium, we investigated the $f s r B$ expression profile in TSBG. $f s r B$ expression also increased until entry into stationary growth phase, reaching $66 \%$ of the expression detected in BHI broth, but then remained relatively constant throughout stationary phase (Fig. 4). These results indicate that $f s r$ expression is variable in different conditions.

We next tested $e b p R$ and $e b p A$ expression using the $\mathrm{P}_{e b p R}::$ and $\mathrm{P}_{e b p A}:$ :lacZ fusions in OG1RF and TX5266 $(\Delta f s r B$ mutant), grown in parallel in TSBG aerobically. Both $e b p R$ and $e b p A$ gene expression profiles followed the same pattern in TX5266 as they did in OG1RF with an increase in expression until the culture reached stationary phase followed by a slow decrease (Fig. 5A). However, ebpR expression was 2-fold lower in OG1RF with $0.3 \beta$-gal units compared to $0.8 \beta$-gal units in TX5266 at entry into stationary phase. Similarly, ebpA expression was 4-fold lower in OG1RF with $3.7 \beta$-gal units compared to $14.1 \beta$-gal units in TX5266 early in stationary phase. These results confirm the role of the Fsr system as a repressor of the ebpR-ebpABC locus in TSBG, adding to the results obtained by microarray at one specific growth phase using cells grown in BHI.

To determine whether the $\mathrm{CO}_{2} / \mathrm{NaHCO}_{3}$ effect on $e b p A$ and $e b p R$ expression is mediated through Fsr, we looked at ebpR and ebpA expression in TX5266 in air and in the presence of $5 \% \mathrm{CO}_{2} / 0.1 \mathrm{M} \mathrm{NaHCO}_{3}$. As shown in Fig. 5B, the ebpA and ebpR expression profiles in TX5266 grown aerobically and in the presence of $5 \%$ $\mathrm{CO}_{2} / 0.1 \mathrm{M} \mathrm{NaHCO}_{3}$ presented the same general profile as in OG1RF (Fig. 2A). That is, ebpA expression increased from $6.8 \beta$-gal units at mid-log growth phase to $13.8 \beta$-gal units at late log growth phase and decreased gradually to $0.6 \beta$-gal units by $24 \mathrm{hr}$ (late stationary). In the presence of $5 \% \mathrm{CO}_{2} / 0.1 \mathrm{M} \mathrm{NaHCO}_{3}$, ebpA expression increased from $16.8 \beta$-gal units at mid-log growth phase to $56.5 \beta$-gal units (5-fold more than with cultures 

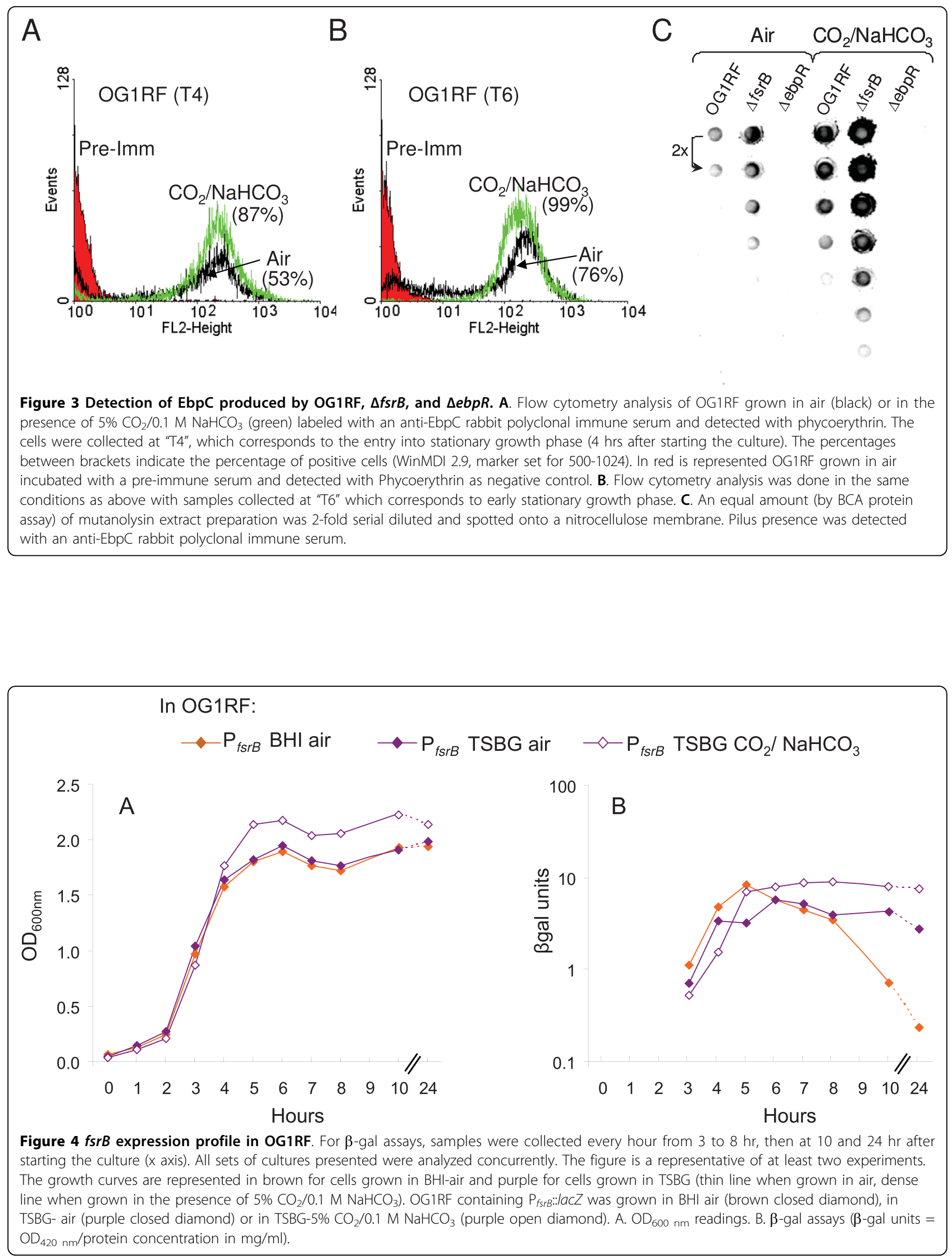
A

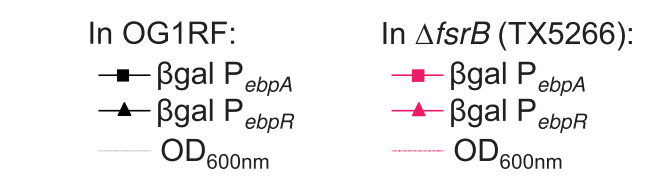

100

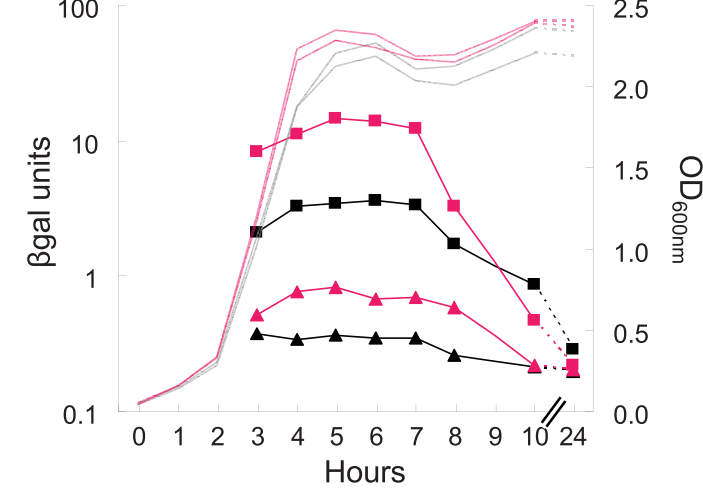

B

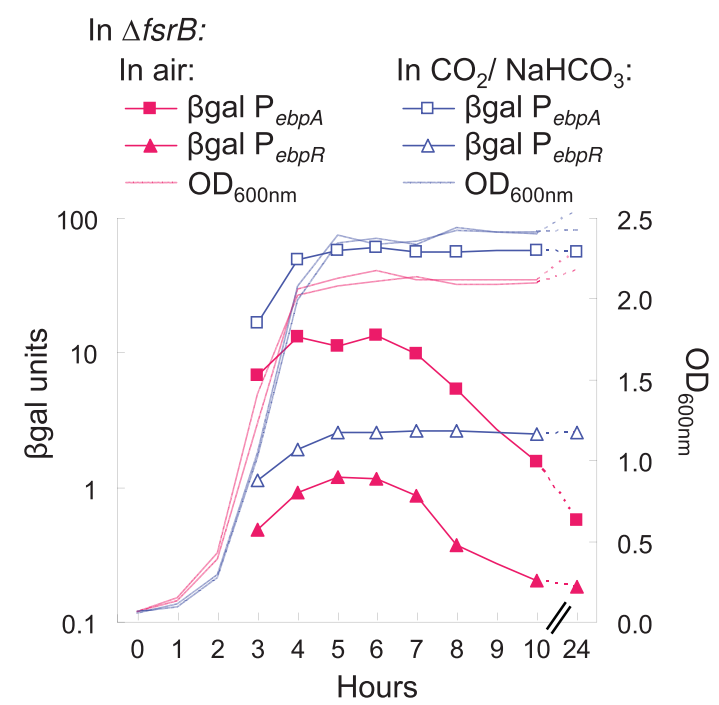

Figure 5 ebpR and ebpA expression profiles in TX5266 ( $\Delta$ fsrB mutant). For $\beta$-gal assays, samples were collected every hour from 3 to 8 hr, then at 10 and $24 \mathrm{hr}$ after starting the culture (x axis). The left axis represents the $\beta$-gal units $\left(\mathrm{OD}_{420 \mathrm{~nm}} /\right.$ protein concentration in $\left.\mathrm{mg} / \mathrm{ml}\right)$. The right axis indicates the $\mathrm{OD}_{600 \mathrm{~nm}}$ readings. All sets of cultures presented were analyzed concurrently. Each figure is a representative of at least

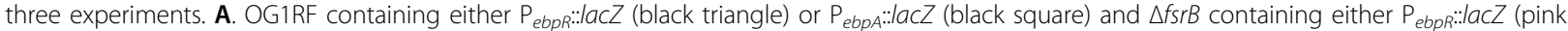
triangle) or $P_{e b p A: I a c Z}$ (pink square) were grown in TSBG aerobically. B. The $\triangle f S r B$ mutant (TX5266) containing either $P_{e b p R: I a c Z}$ (triangle) or $P_{e b p A::}$ lacZ (square) was grown in TSBG aerobically (pink closed symbol) or in the presence of $5 \% \mathrm{CO}_{2} / 0.1 \mathrm{M} \mathrm{NaHCO}_{3}$ (open blue symbol).

grown in air) at $6 \mathrm{hr}$ and remained stable with $55.3 \beta$-gal units at $24 \mathrm{hr}$. ebpR expression profile in TX5266 also remained higher in the presence of $5 \% \mathrm{CO}_{2} / 0.1 \mathrm{M}$ $\mathrm{NaHCO}_{3}$ vs. in aerobic conditions with 0.2 and $2.6 \beta$-gal units, respectively, at $24 \mathrm{hr}$. Finally, we also examined the effect of $\mathrm{CO}_{2} / \mathrm{NaHCO}_{3}$ on $f_{s r B}$ expression by transferring the $\mathrm{P}_{f s r B}:$ :lac $Z$ fusion into OG1RF and followed expression in air and in the presence of $\mathrm{CO}_{2} / \mathrm{NaHCO}_{3}$. In those conditions, $f_{s r} B$ expression was not significantly affected by the presence of $\mathrm{CO}_{2} / \mathrm{NaHCO}_{3}$ (Fig. 4). Our observation of a further increase in $e b p R$ and $e b p A$ expression in TX5266 in the presence of $\mathrm{CO}_{2} / \mathrm{NaHCO}_{3}$ as was observed in OG1RF (Fig. 2A and 5B), together with the lack of an effect of $\mathrm{CO}_{2} / \mathrm{NaHCO}_{3}$ on $f s r$ expression, indicate that $\mathrm{HCO}_{3}{ }^{-}$is not stimulating $e b p R$ and $e b p A$ expression via an effect on the Fsr system.

Finally, at the protein level, pilus production from the $\Delta f s r B$ mutant was compared with that of OG1RF. Cells were grown in TSBG aerobically or in presence of $5 \%$ $\mathrm{CO}_{2} / 0.1 \mathrm{M} \mathrm{NaHCO}_{3}$, and collected at $7 \mathrm{hr}$ (stationary phase). As shown in Fig. 3C, a 3-5 fold increase in pilus production was observed in the $\Delta f s r B$ mutant compared to OG1RF with cells grown aerobically or in presence of $5 \% \mathrm{CO}_{2} / 0.1 \mathrm{M} \mathrm{NaHCO}$. Similarly, 3-5 fold increase in pilus production was also seen with cells grown in the presence of $5 \% \mathrm{CO}_{2} / 0.1 \mathrm{M} \mathrm{NaHCO}$ versus cells grown aerobically for both OG1RF and the $\Delta f s r B$ mutant. In conclusion, the differences observed in $e b p$ mRNA expression levels between OG1RF and the $\Delta f_{s r B}$ mutant and between the conditions used in this study (growth in air versus in the presence of $5 \% \mathrm{CO}_{2} / 0.1 \mathrm{M}$ $\mathrm{NaHCO}_{3}$ ) translated into comparable variations in pilus production at the surface of the cells.

\section{ebpR threshold level}

In the results obtained above, the $e b p R$ and $e b p A$ steadystate mRNA levels followed a similar pattern with $e b p A$ expression being 7 - to 37 -fold higher than $e b p R$ expression, depending on the technique. To investigate whether $e b p A$ expression was directly related to the $e b p R$ expression level, we introduced our previously cloned $e b p R$ under a nisin inducible promoter (pTEX5515) into wild type OG1RF and into its $\triangle e b p R$ mutant, TX5514 [11]. Our previous experiments showed that, even without nisin induction, pilus production was detected at the surface of the cells of the $e b p R$-complemented $\Delta e b p R$ mutant, but not when the $e b p R$ mutant carried the empty plasmid [11]. In this study, we investigated the steady-state mRNA level of $e b p R$ and $e b p A$ in different constructs with or without increasing amounts of nisin, compared to their respective levels in OG1RF carrying the empty vector, using qRT-PCR. The $e b p R$ expression level in the ebpRcomplemented $\triangle e b p R$ mutant was 0.08 (normalized to the $\operatorname{gyr} B$ expression level) without induction, increased 4-fold with $0.5 \mathrm{ng} / \mathrm{ml}$ nisin to 0.26 and reached 9.33 with $10 \mathrm{ng} / \mathrm{ml}$ nisin (Fig. 6), representing a 65-fold increase from 0 to $10 \mathrm{ng} / \mathrm{ml}$ nisin. In the same background, ebpA 
steady-state mRNA levels were only slightly affected with a basal expression level without nisin of 0.6 up to 1.5 with $10 \mathrm{ng} / \mathrm{ml}$ nisin (Fig. 6), a less than a 3-fold increase. However, as expected from our previous results, ebpA expression was 100 -fold lower in the $\triangle e b p R$ mutant carrying the empty vector than in OG1RF carrying the empty vector or in the $e b p R$-complemented $\Delta e b p R$ mutant. We conclude from these experiments that, above the ebpR expression level provided by ebpR copy on pTEX5515 without induction, there is not a strong direct relationship between $e b p R$ expression and $e b p A$ expression.

\section{Bicarbonate effect on ebpA expression}

Studies using $H$. pylori have shown independent effects of $\mathrm{pH}, \mathrm{CO}_{2}$, and bicarbonate on gene expression (these three environmental elements being interconnected in vivo) where $\mathrm{pH}$ appears to be responsible for $H$. pylori orientation [24]. In contrast, bicarbonate and not $\mathrm{CO}_{2}$ appears to be the inducer of expression of the $B$. anthracis toxins

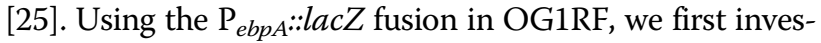
tigated the independent effect of $\mathrm{CO}_{2}$ and $\mathrm{NaHCO}_{3}$ on $e b p A$ in buffered TSBG with or without the presence of $0.1 \mathrm{M} \mathrm{NaHCO}_{3}$ and/or $5 \% \mathrm{CO}_{2}$. $\mathrm{pH}$ was controlled during the experiment and remained at $\mathrm{pH} 7.5 \pm 0.25$. As shown in Fig. 7, ebpA expression in TSBG-air did not differ appreciably from that in TSBG- $5 \% \mathrm{CO}_{2}$, reaching a peak of expression early in stationary phase (15.8 and $14.5 \beta$-gal units, respectively); expression then decreased to 2 and 0.4 $\beta$-gal units, respectively, at $24 \mathrm{hr}$. In the presence of $\mathrm{NaHCO}_{3}, e b p A$ expression peak was $\sim 4$-fold higher with $46.5 \beta$-gal units for the $\mathrm{NaHCO}_{3}$-air culture at entry into stationary phase ( $5 \mathrm{hr}$ ) compared to $9.8 \beta$-gal when the cells were grown without $\mathrm{NaHCO}_{3}$, and $46.0 \beta$-gal units for the $5 \% \mathrm{CO}_{2}$ plus $\mathrm{NaHCO}_{3}$ culture compared to 12.5 $\beta$-gal when grown in presence of $\mathrm{CO}_{2}$ only. The bicarbonate effect persisted late into stationary phase with 42.5 and $40.7 \beta$-gal units when grown in air- $\mathrm{NaHCO}_{3}$ and $\mathrm{CO}_{2}-\mathrm{NaHCO}_{3}$ respectively. A similar profile with increased $e b p R$ expression in the presence of bicarbonate but not in presence of $\mathrm{CO}_{2}$ was also observed (data not shown). Furthermore, the differential effect of $\mathrm{CO}_{2}$ and $\mathrm{NaHCO}_{3}$ was also detected in BHI or when potassium bicarbonate was used as a source for $\mathrm{HCO}_{3}{ }^{-}$(data not shown). Taken together, these results demonstrate that the increase in $e b p R$ and $e b p A$ expression is caused by the addition of $\mathrm{HCO}_{3}{ }^{-}$and not $\mathrm{CO}_{2}$.

Since $\mathrm{NaHCO}_{3}$ is in equilibrium with $\mathrm{H}_{2} \mathrm{CO}_{3}, \mathrm{HCO}_{3}^{-}$, and $\mathrm{CO}_{3}{ }^{2-}$ depending of the $\mathrm{pH}$, temperature and partial pressure of $\mathrm{CO}_{2}$, we next tested a possible $\mathrm{pH}$ effect on $e b p A$ expression when cells were grown in buffered TSBG. In a preliminary experiment, OG1RF $\left(\mathrm{P}_{\text {ebp } A}:\right.$ lac $\left.Z\right)$ was grown in buffered TSBG with $\mathrm{pH}$ ranging from 5 to 9. Severe growth inhibition was observed at $\mathrm{pH} 5$ and 9 with mild growth inhibition at $\mathrm{pH} 6$, compared to unaffected growth at $\mathrm{pH} 7$ and 8 (data not shown). Consequently, further experiments were conducted with buffered media with $\mathrm{pH} 7$ and 8 only. Without the addition of sodium bicarbonate, ebpA expression levels of cells grown at $\mathrm{pH} 8 \pm 0.25$ were comparable with the levels in cells grown at $\mathrm{pH} 7 \pm 0.25$ (Fig. 8). However, adding $\mathrm{NaHCO}_{3}$ led to a 4- to 5 -fold increase in $\beta$-gal production at either $\mathrm{pH}$ ( $\mathrm{pH}$ was controlled during the experiment and remained constant with a \pm 0.25 variation). For example, $\beta$-gal units were 9.4 at $6 \mathrm{hr}$ for cells grown at $\mathrm{pH} 7$-air, while at the same time point and $\mathrm{pH}$, $\beta$-gal units were 40.1 when grown in the presence of $\mathrm{NaHCO}_{3}$. In conclusion, between $\mathrm{pH}$ (range 7-8), $\mathrm{CO}_{2}$

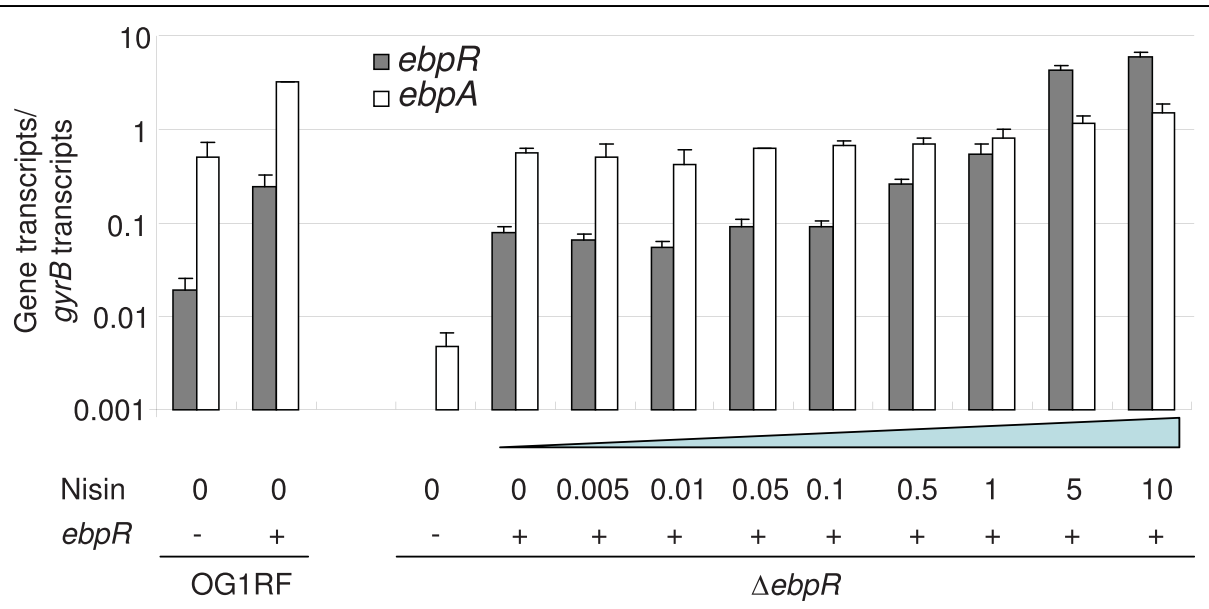

Figure 6 Effect of nisin induction on ebpR and ebpA expression. Cells were grown to an $\mathrm{OD}_{600 \mathrm{~nm}}$ of $\sim 0.8$ ( 3 hr, late log exponential growth phase) and at this point cells were left untreated (0) or treated with increasing concentration of nisin (from 0.005 to $10 \mathrm{ng} / \mathrm{ml}$ ). Then, cells were collected and RNA extracted. After reverse transcription, ebpA and ebpR CDNA was quantified by real time PCR. The strains were OG1RF or $\triangle e b p R$ (TX5514) carrying either the empty plasmid (-) or ebpR in trans under the nisin promoter (+). ebpR (gray bars) and ebpA (white bars) transcript levels were normalized with gyrB transcript levels. The data correspond to the mean of two independent experiments. 
$\mathrm{OG} 1 \mathrm{RF}+\mathrm{P}_{\text {ebpA }}:: / \mathrm{lacZ}$ grown in TSBG
$\rightarrow-$ air $\rightarrow-\mathrm{CO}_{2} \rightarrow-\mathrm{NaHCO}_{3} /$ air $\rightarrow-\mathrm{NaHCO}_{3} / \mathrm{CO}_{2}$
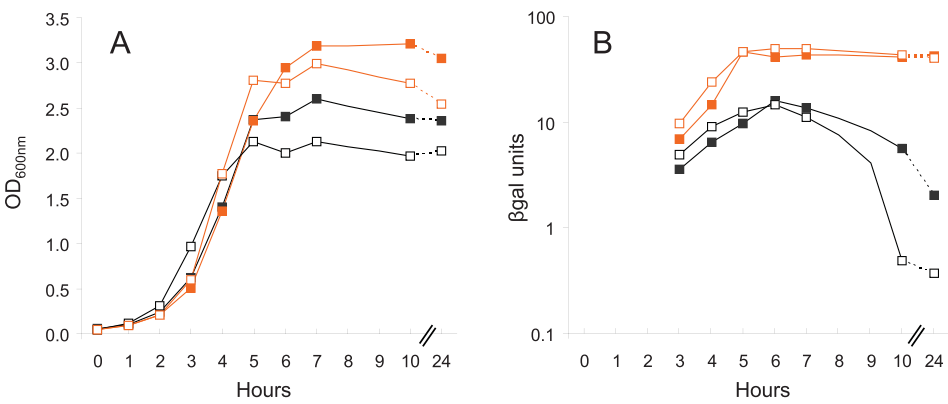

Figure 7 ebpA expression affected by $\mathrm{NaHCO}_{3}$, and not $\mathrm{CO}_{2}$. For $\beta$-gal assays, samples were collected every hour from 3 to $8 \mathrm{hr}$, then at 10 and $24 \mathrm{hr}$ after starting the culture (x axis). Growth curves of OG1RF containing $\mathrm{P}_{\text {ebp } A:: / a c Z}$ are shown in air with a thin gray line, in $\mathrm{NaHCO}_{3} / \mathrm{air}$ with thin orange line, in $\mathrm{CO}_{2}$ with a dense gray line, and in $\mathrm{NaHCO}_{3} / \mathrm{CO}_{2}$ with a dense orange line. The $\beta$-gal assays for OG1RF containing $P_{\text {ebpa: }}$ lacZ are represented with closed black square, closed orange square, open black square, and open orange square when the cells were grown in air, $5 \% \mathrm{CO}_{2}, \mathrm{NaHCO}_{3}$-air, and $\mathrm{NaHCO}_{3}-5 \% \mathrm{CO}_{2}$, respectively. All sets of cultures presented were analyzed concurrently. This figure is a representative of at least two experiments. $A . \mathrm{OD}_{600} \mathrm{~nm}$ readings. B. $\beta$-gal assays ( $\beta$-gal units $=\mathrm{OD}_{420} \mathrm{~nm} /$ protein concentration in $\mathrm{mg} / \mathrm{ml}$ ).

and bicarbonate, bicarbonate appears to be the main environmental inducer of the $\operatorname{ebp} A B C$ operon.

\section{Effect of bicarbonate exposure on the OG1RF transcriptome}

In an effort to begin to delineate the "bicarbonate regulon", we used microarray analysis with cells grown to late exponential growth phase $(3 \mathrm{hr}$ ) and then submitted to a 15 min exposure with $0.1 \mathrm{M} \mathrm{NaHCO}_{3}$. Our goal was to define the first set of genes affected by the presence of bicarbonate. Out of the 73 genes that were differentially expressed (abs(fold) $>2, P<0.05$, data deposited at ArrayExpress, additional file 1), only two genes were repressed by the presence of bicarbonate more than 5-fold (EF0082 and EF0083 with 9.9- and 7fold, respectively) while four genes were activated more than 5-fold (EF0411-3 with 10-fold, and EF2642 with 6.5-fold). EF0082 is part of the ers regulon (ers encodes a PrfA-like protein involved in the E. faecalis stress response [26,27]), but its function remains unknown, as is also true for EF0083. The EF0411-3 genes appear to be organized as an operon and encode proteins with the characteristics of a mannitol PTS system. EF2642 also appeared to be expressed in an operon with EF2641, which was also activated (4.1-fold, $P<0.05)$. EF2641 and EF2642 encode a putative glycine betaine/L-proline ABC transporter ATP-binding protein and permease protein, respectively. Those results were confirmed by qRT-PCR with a decrease of 32-fold for EF0082 in the presence of bicarbonate while EF0411 and EF2641 expression levels increased in the presence of bicarbonate by 24 -fold and 8.5 -fold, respectively (results not shown). The ebpR-ebpABC locus did not appear to be affected in these conditions (late log growth phase following a $15 \mathrm{~min}$. incubation time with $0.1 \mathrm{M} \mathrm{NaHCO}$ ), suggesting that the bicarbonate effect on the $e b p R$ $e b p A B C$ locus may be indirect, requiring a cascade of events.

\section{Discussion}

We previously noted that EbpR shares homology with the AtxA/Mga family [11]. Regulators in this family have been shown to be active toward their target(s) in the presence of $\mathrm{CO}_{2}$ or $\mathrm{CO}_{2} / \mathrm{HCO}_{3}{ }^{-}$. While atx $A$ is

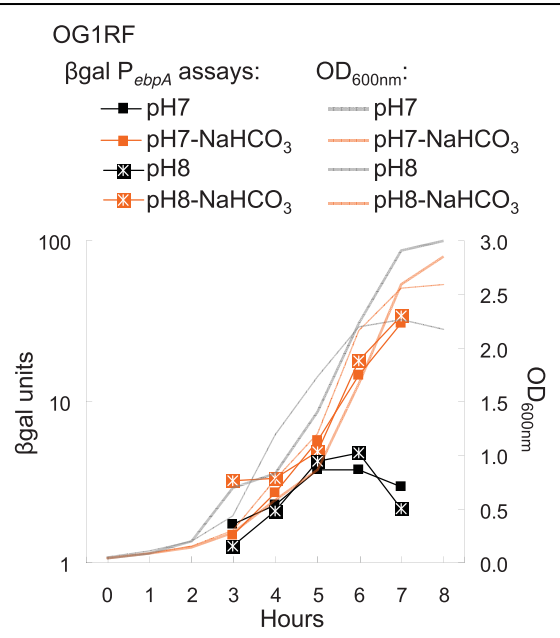

Figure $8 \mathrm{pH}$ and $\mathrm{NaHCO}_{3}$ effect on ebpA expression. OG1RF containing $P_{e b p A:: / a c Z}$ was used in these experiments. Growth curves are represented in thin gray line for $\mathrm{pH} 7$ aerobically, thin orange line for $\mathrm{pH}$ 7-Air $/ \mathrm{NaHCO}_{3}$, dense gray line for $\mathrm{pH} 8$ aerobically, and dense orange line for $\mathrm{pH}$ 8-Air/ $/ \mathrm{NaHCO}_{3}$. All sets of cultures presented were analyzed concurrently. This figure is a representative of at least two experiments. A. $\mathrm{OD}_{600 \mathrm{~nm}}$ readings. B. $\beta$-gal assays $(\beta$ gal units $=\mathrm{OD}_{420 \mathrm{~nm}} /$ protein concentration in $\mathrm{mg} / \mathrm{ml}$ ). 
constitutively expressed, $a c p A$ and $a c p B$ (also members of the AtxA/Mga family) as well as $m g a$ are activated by the presence of $\mathrm{CO}_{2}$. In the work described here, we present evidence that bicarbonate is a strong inducer of the ebpR-ebpABC locus and consequently of pilus presence. Among the other environmental conditions tested, $\mathrm{pH}$ appears to have a weak effect in the limited conditions tested, while $\mathrm{CO}_{2}$ had no effect. Although $e b p R$ and $e b p A$ expression levels share a similar pattern, we were not able to show that an increase in $e b p R$ expression, beyond a certain level, resulted in a proportional further increase of $e b p A$ expression. Finally, the Fsr system affects expression of the ebpR-ebpABC locus independently of either the growth phase or the presence of bicarbonate.

It is interesting that ebpABC, also shown to be important for E. faecalis virulence, responded to bicarbonate. Bicarbonate influences expression of $a d c A$ (encoding an adhesin [28]) and $k f c$ (encoding a factor important for gut colonization) in C. rodentium, which are controlled by the bicarbonate regulator RegA [19], as well as the three toxin genes in B. anthracis [25]. Bicarbonatemediated transcriptional activation may be a system to sense a change in the environment. For example, the proximal portion of the duodenum is exposed to intermittent pulses of gastric $\mathrm{H}(+)$ discharged by the stomach. To protect the epithelial surface, at least two $\mathrm{HCO}_{3}{ }^{-} / \mathrm{Cl}^{-}$anion exchangers have been described as being responsible for the release of $\mathrm{HCO}_{3}{ }^{-}$into the duodenum lumen [29]. We postulate that E. faecalis may be sensing this signal and consequently produces adhesin structures like the ebpABC-encoded pili to favor colonization of the intestinal track, similar to $a d c A$ in $C$. rodentium, the expression of which is controlled by bicarbonate and whose gene product has been shown to be involved in adherence to mammalian cells [28].

From the various results obtained in this study where expression of $\operatorname{ebp} A$ followed the same expression profile as the $e b p R$ expression, we postulated that the ebpA expression level was proportionally linked to the $e b p R$ expression. To investigate our hypothesis, we used an $e b p R$ construct under the control of a nisin regulated promoter. However, as shown in Fig. 6, the ebpR expression level was already 2-fold higher in the complemented $\triangle e b p R$ strain (in the absence of nisin) when compared to its native level in wild type OG1RF $(0.06$ vs. 0.03) and was not detected (with a detection level of $10^{-5}$ the level of $g y r B$ ) in the $e b p R$ deletion mutant with the empty plasmid. We did not observe a strong effect on ebpA expression after nisin induction, leading to the conclusion that $e b p R$ expression was already above the threshold required to significantly increase $e b p A$ expression. We tried another construct pCJK96 (rhamnose induction [30]), but faced the same issues (data not shown). Thus, although we did not determine the threshold necessary for the ebpA expression, the presence of $e b p R$ was confirmed to be critical for $e b p A$ expression.

One difference between $e b p R$ and $e b p A$ expression profiles in the presence of bicarbonate (vs. absence of bicarbonate) occurred after entry into stationary phase. $e b p R$ and $e b p A$ expression without bicarbonate begins to decrease, while it remained constant in the presence of bicarbonate. This difference may be explained either by an induction pathway that remains active (in the presence of $\mathrm{HCO}_{3}{ }^{-}$) in stationary phase or by inhibition early in stationary phase of a repression pathway (e.g., quorum sensing or phase dependent regulator). The first mechanism would also explain the slight difference observed in the presence of $\mathrm{HCO}_{3}{ }^{-}$during log growth phase. A potential candidate is a RegA homologue, an AraC/XylS-like regulator from C. rodentium [19]. Among the E. faecalis AraC/XylS-like regulators, none shares additional significant similarity with RegA. A second possibility would be a quorum sensing mechanism. A likely candidate would be the Fsr system [6]. However, the Fsr system, although a weak repressor of $e b p R$, does not appear to mediate the bicarbonate effect, since a similar $e b p A$ expression pattern compared to OG1RF was observed in an $f_{s r} B$ mutant in the presence or absence of bicarbonate. Finally, we looked at the stress response pathway including ers and its regulon [26,27]. Interestingly, several members of the ers regulon were affected by a 15 min bicarbonate exposure, including EF0082-3 and EF0104-6. However, although both operons are activated by ers, EF0082-3 were strongly repressed (-8 fold), while EF0104-6 were activated (3 fold) by bicarbonate exposure. In addition, ers was not affected. In conclusion, the regulation pathways in $E$. faecalis resemble a network with several targets genes being under the control of independent regulation pathways illustrated by ebpR-ebpABC being independently a member of the bicarbonate and the $f s r$ regulon, and EF0082 a member of the bicarbonate and ers regulon.

We also showed using microarray profiling that expression of many other genes (mostly PTS systems and $A B C$ transporters) was altered in response to $\mathrm{HCO}_{3}{ }^{-}$. Among those genes are EF2641 and EF2642, which encode a putative glycine betaine/L-proline $A B C$ transporter and permease protein, respectively. Interestingly, this $\mathrm{ABC}$ transporter shares some homology with the bicarbonate transporter described in $B$. anthracis (Tau family of ABC transporters) [25]. However, we did not find a TauA motif, that has been proposed as the bicarbonate binding motif, associated with the EF2641-2 locus or in available $E$. faecalis genomes including OG1RF. Interestingly, expression of ebpR-ebpABC was not affected by the 15 minutes bicarbonate exposure. 
Those results could be explained by the need of a cascade of events for a bicarbonate effect on $e b p R-e b p A B C$ expression or that the cells need an unknown factor, not present at the growth phase tested. Indeed, as seen in Fig. 2, Fig. 7, and Fig. 8, the greatest difference in ebpR-ebpABC expression was observed from mid stationary to late stationary growth phases (conditions that we found unsuited for microarray due to low and unstable mRNA expression). In conclusion, although we did not detect an effect of 15 minutes bicarbonate exposure on $e b p R-e b p A B C$ by microarray, the bicarbonate regulon was shown to share some components with the ers regulon and a later bicarbonate effect on $e b p$ expression was shown by $\beta$-gal assays, qRT-PCR and western blot.

Finally, we have previously shown in the rat endocarditis model that an $f s r B$ mutant is less attenuated than a gelE mutant [31]. Since, in the absence of the Fsr system, weak transcription of gelE was detected, it was postulated that the increase in virulence of the $f s r B$ mutant compared to the gelE mutant might be a consequence of the residual production of gelatinase. However, since pilus production is also important in the rat endocarditis model [9], we can now postulate that, in the absence of the Fsr system as well as in presence of bicarbonate (by far the most important buffer for maintaining acid-base balance in the blood), pilus production increases, potentially causing the increased virulence of the $f s r B$ mutant compared to the gelE mutant.

\section{Conclusion}

Considering that bicarbonate is an activator of the ebpRebpABC locus and that this locus is ubiquitous among $E$. faecalis isolates (animal, commensal, and clinical isolates) [9], these results seem to suggest an intrinsic aptitude of this species for pilus production which could play an important role in colonization of both commensal and pathogenic niches. Future studies should assess expression of the ebpR-ebpABC locus and the role of pili in a gut colonization model.

\section{Methods}

\section{Strains, media, growth conditions}

The strains used in this study are listed in Table 1. All strains were routinely grown in brain heart infusion broth (BHI broth; Difco Laboratories, Detroit, Mich.) at $150-200 \mathrm{rpm}$ aerobically or on $\mathrm{BHI}$ agar at $37^{\circ} \mathrm{C}$, unless otherwise indicated. Tryptic soy broth (Difco Laboratories, Detroit, Mich.) with $0.25 \%$ glucose (TSBG) was used to test strains for biofilm production, one of the assays where both $e b p R$ and $e b p A$ mutants are attenuated compared to OG1RF $[9,11]$.

For all assays, strains were first streaked on BHI agar with the appropriate antibiotics, as needed. Five to ten colonies were inoculated into BHI broth and grown overnight (with antibiotics when appropriate), then cells were diluted so that the starting optical density at 600 $\mathrm{nm}$ was 0.05 . For cultures grown in the presence of bicarbonate, a solution of $9 \%$ sodium bicarbonate was freshly prepared, filtered, and added for a final concentration of $0.8 \%$ ( $0.1 \mathrm{M}$ final). The cultures were buffered with $100 \mathrm{mM}$ 4-(2-hydroxyethyl)-1-piperazineethanesulfonic acid (HEPES) for a final $\mathrm{pH}$ of $7.5 \pm 0.25$ or as indicated. For comparison between cultures grown with and without bicarbonate, an equal volume of water was added to the culture without added bicarbonate. The cultures were then placed on a rotating platform set at $150 \mathrm{rpm}$ at $37^{\circ} \mathrm{C}$ aerobically or in a $5 \% \mathrm{CO}_{2}$ atmosphere. The $\mathrm{pH}$ was monitored during growth and remained at $7.5 \pm 0.25$. For each set of results, the cultures and following assays were analyzed concurrently. The presence of none of the four lac $Z$ constructs $\left(\mathrm{P}_{T C V}, \mathrm{P}_{e b p A}, \mathrm{P}_{e b p R}\right.$, and $\mathrm{P}_{f s r B}$ ) affected the growth of their host (OG1RF, $\Delta e b p R$, or $\Delta f s r)$ in the conditions tested. To obtain accurate readings, cultures from $3 \mathrm{hr}$ to $24 \mathrm{hr}$ were diluted 5 -fold before determining the OD.

\section{Construction of the ef 1091 promotor fusion}

The same protocol was used to create the $\mathrm{P}_{\text {ebp }}$ ::lac $Z$ fusion as previously described for the $\mathrm{P}_{e b p R}:$ :lac $Z$ fusion [11]. The primers cgggatccaagactacgccgaaaacc (introduced restriction sites are highlighted in bold) and ggaattcacacgaatgatttcttcca were used to amplify from 221 bp upstream to $80 \mathrm{bp}$ downstream of the ebpA start codon (301 bp total). The fragment was amplified by PCR, cloned into pGEM-T-Easy vector (Promega, Madison, WI), sequenced, and then subcloned into pTCVlacZ [32] using EcoRI and BamHI sites. After transfer into OG1RF, TX5266 $(\Delta f s r B)$, and TX5514 $(\Delta e b p R)$, the plasmids were then purified and confirmed again by sequencing using previously published primers Vlac1 and Vlac2, which are located upstream and downstream of the promoter area [32].

\section{$\beta$-galactosidase assay}

Assays were performed according to the protocol of Hancock et al. [33] with some modifications. Following growth in the designated culture conditions and at each time point mentioned, a sample was collected $\left(\sim 2 \times 10^{9}\right.$ $\mathrm{CFU})$, centrifuged, and the pellet frozen until used. Cell pellets were resuspended in $1 \mathrm{ml}$ of $1 / 10 \mathrm{Z}$ buffer $(\mathrm{Z}$ buffer: $60 \mathrm{mM} \mathrm{Na}{ }_{2} \mathrm{HPO}_{4}, 40 \mathrm{mM} \mathrm{NaH} \mathrm{PO}_{4}, 10 \mathrm{mM}$ $\mathrm{KCl}, 1 \mathrm{mM} \mathrm{MgSO}$, $[\mathrm{pH} 7.0]$ ). The cell suspension was transferred to a $2.0-\mathrm{ml}$ tube containing a $0.5 \mathrm{ml}$ volume of $0.1 \mathrm{~mm}$ diameter zirconia beads (BioSpec Products, Bartlesville, Okla.). The cells were disrupted using a vortex adapter for $5 \mathrm{~min}$, then centrifuged at $13.6 \mathrm{~K} \mathrm{rpm}$ for $1 \mathrm{~min}$. Serial dilution of the aqueous layer was used in a $\beta$-galactosidase assay as described by Miller [34] with a final volume of $200 \mu \mathrm{l}$ (96-wells microtiter plate). 
Table 1 Strains and plasmids used in this study

\begin{tabular}{|c|c|c|}
\hline $\begin{array}{l}\text { Strain or } \\
\text { Plasmid }\end{array}$ & Relevant characteristics & $\begin{array}{l}\text { Source or } \\
\text { reference }\end{array}$ \\
\hline \multicolumn{3}{|l|}{ E. coli strains } \\
\hline TG1 & E. coli general cloning host & [35] \\
\hline \multicolumn{3}{|l|}{$\begin{array}{l}\text { E. faecalis } \\
\text { strains }\end{array}$} \\
\hline OG1RF & E. faecalis. Fus ${ }^{R}$, Rif ${ }^{R}$ & [36] \\
\hline TX5266 & OG1RF fsrB deletion mutant, deletion from bp 79 to 684 of $f_{s r B}$. Fus ${ }^{R}$, Rif $^{R}$ & [6] \\
\hline TX5514 & OG1RF ebpR deletion mutant, deletion from -5 bp to +1337 bp of ebpR. Fus ${ }^{R}$, Rif ${ }^{R}$ & {$[11]$} \\
\hline TX5584 & TX5514(pMSP3535). Erm ${ }^{R}$, Fus $^{R}$, Rif $^{R}$ & [11] \\
\hline TX5582 & TX5514(pTEX5515); ebpR mutant containing ebpR gene cloned into pMSP3535. Erm ${ }^{R}$, Fus ${ }^{R}$, Rif ${ }^{R}$ & {$[11]$} \\
\hline TX5583 & OG1RF(pMSP3535). Erm ${ }^{R}$, Fus $^{R}$, Rif $^{R}$ & This study \\
\hline TX5581 & OG1RF(pTEX5515); ebpR mutant containing ebpR gene cloned into pMSP3535. Erm $^{R}$, Fus ${ }^{R}$, Rif ${ }^{R}$ & This study \\
\hline \multicolumn{3}{|l|}{ Plasmids } \\
\hline pTCV-lacZ & Shuttle vector containing promoterless lacZ. Erm ${ }^{R}$ & [32] \\
\hline pMSP3535 & Nisin inducible expression shuttle vector with $\mathrm{pAM} \beta 1$ and ColE1 replicons. Erm ${ }^{R}$ & [37] \\
\hline pTEX5269 & 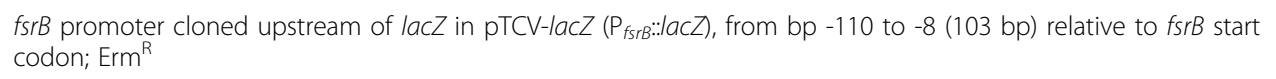 & [6] \\
\hline pTEX5585 & 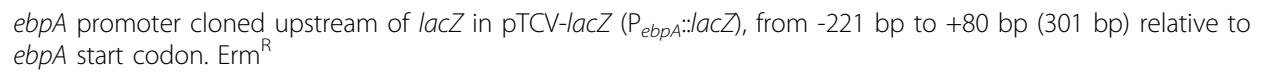 & This study \\
\hline pTEX5586 & 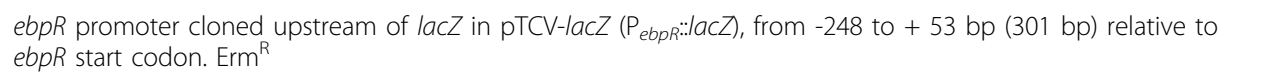 & [11] \\
\hline pTEX5515 & $\begin{array}{l}\text { pMSP3535 with ebpR from }-20 \text { bp to }+1561 \text { bp from the ATG. This ebpR fragment contains the full ORF and } \\
\text { the RBS of ebpR. ErmR }\end{array}$ & [11] \\
\hline
\end{tabular}

Twenty-five $\mu \mathrm{l}$ were assayed for total protein using the BCA protein assay kit (Pierce, Rockford, IL). Due to day to day variability, only data obtained within the same experiment (with cultures grown and samples assayed in parallel) were used for comparisons. To normalize the samples assayed in parallel, we used the total protein content as described in [33]. Experiments were repeated on at least two independent occasions and $\beta$-gal units for each experiment corresponded to $\mathrm{OD}_{420 \mathrm{~nm}} /$ protein concentration in $\mathrm{mg} / \mathrm{ml}$. The figures show data from one representative experiment.

\section{RNA purification for qRT-PCR}

To follow gene expression in OG1RF during growth in TSBG at $37^{\circ} \mathrm{C}, 150 \mathrm{rpm}$, samples were collected every hour from three to $7 \mathrm{hr}$ after starting the culture. For the nisin induction assay, cells were grown to an $\mathrm{OD}_{600}$ $\mathrm{nm}$ of $\sim 0.8$ (3 hr, late log exponential growth phase), and at this point cells were left untreated or treated with increasing concentration of nisin (from $0.005 \mathrm{ng} / \mathrm{ml}$ to $10 \mathrm{ng} / \mathrm{ml}$ ). In each case, an equivalent of $\mathrm{OD}_{600 \mathrm{~nm}} \sim 1$ of cells was centrifuged, and the pellet was conserved at $-80^{\circ} \mathrm{C}$. RNA and cDNA were prepared using the methods described before [8]. Quantitative PCR on cDNA was performed using SYBR green PCR master mix kit (Applied Biosystems, Foster City, CA) and a 7500 RealTime PCR system (Applied Biosystems). ebpA was selected for those experiments because it is the first gene of the $\operatorname{ebp} A B C$ operon. The following primers were used: $g y r B$, accaacaccgtgcaagcc and caagccaaaacaggtcgcc; $e b p A$, aaaaatgattcggctccagaa and tgccagattcgctctcaaag; $e b p R$, acggatatggcaaaacy and agaagagcgactaatattgatgg; EF0082, aaactccttgaactgattgg and ccagataaagaatgccata; EF0411, agctgaactaacggaacaag and tcttttaagagcgaaaccac; and EF2641, attcgtggtgttcctaaaga and catcccaccagataattgac. For each primer set, a reference curve was established using a known amount of gDNA purified from OG1RF. The amount (in $\mathrm{ng} / \mathrm{ml}$ ) obtained for the gene of interest transcripts were normalized with the amount of $g y r B$ transcripts.

Microarray analysis

The BHI cultures of OG1RF were started as described above. Cultures were grown to an $\mathrm{OD}_{600 \mathrm{~nm}}$ of $\sim 0.8$ (3 $\mathrm{hr}$, late log exponential growth phase), and at this point $25 \mathrm{ml}$ of culture were centrifuged and resuspended in either BHI-buffered or BHI-buffered with $0.1 \mathrm{M}$ bicarbonate, incubated for $15 \mathrm{~min}$ at $37^{\circ} \mathrm{C} @ 150 \mathrm{rpm}$, then centrifuged and the pellet conserved at $-80^{\circ} \mathrm{C}$ until use. The microarray consists of 70-mer oligonucleotides that were printed on a GAPS II slide (Corning Incorporated, Corning, NY) at the University of Texas Medical School Microarray Core Laboratory. The RNA preparation, probe labeling, hybridization, data acquisition and statistical analysis were performed following the same methods as described previously [8]. The results of the bicarbonate induction are deposited at ArrayExpress 
http://www.ebi.ac.uk/microarray-as/ae/ under accession number E-MEXP-2518.

\section{Flow cytometry analysis}

An equivalent of $\sim 1 \mathrm{OD}_{600} \mathrm{~nm}$ of culture was collected for flow cytometry analysis, centrifuged and the pellet frozen until used. The pellet was then washed twice with $1 \mathrm{ml}$ of PBS $\left(80 \mathrm{mM} \mathrm{Na}_{2} \mathrm{HPO}_{4}, 20 \mathrm{mM} \mathrm{NaH} \mathrm{PO}_{4}\right.$, $100 \mathrm{mM} \mathrm{NaCl}, \mathrm{pH} 7.5$ ), resuspended in $0.5 \mathrm{ml}$ of paraformaldehyde buffer $(4.4 \% \mathrm{w} / \mathrm{v}$ paraformaldehyde, 30 $\mathrm{mM} \mathrm{Na}_{2} \mathrm{HPO}_{4}, 30 \mathrm{mM} \mathrm{NaH} \mathrm{PO}_{4}$ ), and incubated at RT for $15 \mathrm{~min}$. The cells were pelleted and resuspended in $0.5 \mathrm{ml}$ of PBS-2\% BSA, and subsequently placed at $-80^{\circ}$ $\mathrm{C}$ for at least an hour. Before labeling, the cells were washed twice in PBS. A pellet corresponding to $10^{8}$ CFU was resuspended in $100 \mu \mathrm{l}$ of PBS with the antiEbpC polyclonal rabbit serum at a 1:1000 dilution, and incubated at $4{ }^{\circ} \mathrm{C}$ for $2 \mathrm{~h}$. After centrifugation and two washes with PBS, the cells were resuspended in $100 \mu \mathrm{l}$ of PBS with R-Phycoerythrin-conjugated affinipure $\mathrm{F}$ $\left(a^{\prime}\right)_{2}$ goat anti-Rabbit IgG (H+L) (Jackson ImmunoResearch Laboratories, Inc) at a dilution of 1:100, and incubated at $4^{\circ} \mathrm{C}$ for $2 \mathrm{~h}$. The cells were then washed twice, resuspended in $1 \mathrm{ml} \mathrm{PBS}$, and conserved at $4^{\circ} \mathrm{C}$ until they were analyzed with a BD FACSCalibur ${ }^{\mathrm{m}}$ sys- $^{-}$ tem (BD Biosciences, San Jose, CA).

\section{Protein extraction and dot blot}

Surface protein extracts from E. faecalis OG1RF and derivatives were prepared using mutanolysin (Sigma Chemical Co., St. Louis, MO). Cells grown at $37^{\circ} \mathrm{C}$ in specified conditions were collected at $7 \mathrm{hr}$ after starting the culture. The cells were washed and resuspended in $1 / 100$ volume of $0.02 \mathrm{M}$ Tris- $\mathrm{HCl}(\mathrm{pH} 7.0)-0.01 \mathrm{M}$ $\mathrm{MgSO}_{4}$ buffer. Mutanolysin was added to a final concentration of $5 \mathrm{U}$ for an equivalent of $1 \mathrm{OD}_{600 \mathrm{~nm}}$ of cells and incubated at $37^{\circ} \mathrm{C}$ for $1 \mathrm{hr}$. The supernatants were collected after centrifugation at $13.6 \mathrm{~K} \mathrm{rpm}$ for 5 min. An equal amount of mutanolysin extract preparation (quantified using the BCA protein assay kit) was 2fold serial diluted and was spotted onto NitroPure (GE Water and Process Tech., Watertown, MA) using the Bio-Dot ${ }^{\circ}$ Microfiltration Apparatus (Biorad, Hercules, $\mathrm{CA})$. The membranes were incubated with anti-EbpC rabbit polyclonal antiserum [9] at a dilution of 1:2000, followed by protein A-horseradish peroxidase conjugate (1:5000). Pilus production was then revealed using chemiluminescence (Amersham, Piscataway, NJ).

Additional file 1: Microarray results following 15 minutes bicarbonate induction. Define the first set of genes affected shortly after addition of bicarbonate to the medium.

Click here for file

[http://www.biomedcentral.com/content/supplementary/1471-2180-1017-S1.DOC]

\section{Acknowledgements}

We are grateful to K.V. Singh, T. M. Koehler, D. A. Garsin, J.R. Galloway-Pena and S. R. Nallapareddy for helpful discussions. This study was supported by grant NIH R37 Al47923 from the Division of Microbiology and Infectious Diseases, NIAID, to B.E.M.

\section{Author details}

${ }^{1}$ Division of Infectious Diseases, Department of Medicine, University of Texas Medical School, (6431 Fannin) Houston, Texas (77030), USA. ${ }^{2}$ Center for the Study of Emerging and Reemerging Pathogens, University of Texas Medical School, (6431 Fannin) Houston, Texas (77030), USA. ${ }^{3}$ Department of Microbiology and Molecular Genetics, University of Texas Medical School, (6431 Fannin) Houston, Texas (77030), USA.

\section{Authors' contributions}

$A B$ and $B E M$ designed the study. $A B$ performed the experiments except the beta-galactose assays done also by $L C T$. $A B$ wrote the draft of the manuscript. BEM assisted in critical review of the manuscript. All authors read and approved the final manuscript.

Received: 4 June 2009

Accepted: 21 January 2010 Published: 21 January 2010

\section{References}

1. Murray BE: The life and times of the Enterococcus. Clin Microbiol Rev 1990, 3(1):46-65.

2. Ogier JC, Serror P: Safety assessment of dairy microorganisms: The Enterococcus genus. Int J Food Microbiol 2008, 3:291-301.

3. Murray BE: Enterococci. Infectious diseases W. B. Saunders Company, Philadelphia, PaGorbach SL, Bartlett JG, Blacklow NR, 2 1998, 1723-1730.

4. Edmond MB, Wallace SE, McClish DK, Pfaller MA, Jones RN, Wenzel RP: Nosocomial bloodstream infections in United States hospitals: a threeyear analysis. Clin Infect Dis 1999, 29(2):239-244.

5. Qin X, Singh KV, Weinstock GM, Murray BE: Effects of Enterococcus faecalis fsr genes on production of gelatinase and a serine protease and virulence. Infect Immun 2000, 68(5):2579-2586.

6. Qin X, Singh KV, Weinstock GM, Murray BE: Characterization of fsr, a regulator controlling expression of gelatinase and serine protease in Enterococcus faecalis OG1RF. J Bacteriol 2001, 183(11):3372-3382.

7. Nakayama J, Chen S, Oyama N, Nishiguchi K, Azab EA, Tanaka E, Kariyama R, Sonomoto K: Revised model for Enterococcus faecalis fsr quorum-sensing system: the small open reading frame $f s r D$ encodes the gelatinase biosynthesis-activating pheromone propeptide corresponding to staphylococcal agrD. J Bacteriol 2006, 188(23):8321-8326.

8. Bourgogne A, Hilsenbeck SG, Dunny GM, Murray BE: Comparison of OG1RF and an isogenic fsrB deletion mutant by transcriptional analysis: the Fsr system of Enterococcus faecalis is more than the activator of gelatinase and serine protease. J Bacteriol 2006, 188(8):2875-2884.

9. Nallapareddy SR, Singh KV, Sillanpaa J, Garsin DA, Hook M, Erlandsen SL, Murray BE: Endocarditis and biofilm-associated pili of Enterococcus faecalis. J Clin Invest 2006, 116(10):2799-2807.

10. Singh KV, Nallapareddy SR, Murray BE: Importance of the ebp (Endocarditis- and Biofilm-Associated Pilus) locus in the pathogenesis of Enterococcus faecalis ascending urinary tract infection. J Infect Dis 2007, 195(11):1671-1677.

11. Bourgogne A, Singh KV, Fox KA, Pflughoeft KJ, Murray BE, Garsin DA: EbpR is important for biofilm formation by activating expression of the endocarditis and biofilm-associated pilus operon (ebpABC) of Enterococcus faecalis OG1RF. J Bacteriol 2007, 189(17):6490-6493.

12. Uchiyama $\mathrm{H}$, Hayashi $\mathrm{H}$, Suzuki Y: Functional characterization of $\mathrm{Cl}^{-} / \mathrm{HCO}_{3}$ exchange in villous cells of the mouse ileum. Biomed Res 2006, 27(6):265-274

13. Wong AC, Bergdoll MS: Effect of environmental conditions on production of toxic shock syndrome toxin 1 by Staphylococcus aureus. Infect Immun 1990, 58(4):1026-1029.

14. Iwanaga M, Yamamoto K: New medium for the production of cholera toxin by Vibrio cholerae 01 biotype El Tor. J Clin Microbiol 1985, 22(3):405-408.

15. Caparon MG, Geist RT, Perez-Casal J, Scott JR: Environmental regulation of virulence in group $A$ streptococci: transcription of the gene encoding $M$ 
protein is stimulated by carbon dioxide. J Bacteriol 1992,

174(17):5693-5701.

16. Koehler TM: Bacillus anthracis genetics and virulence gene regulation. Curr Top Microbiol Immunol 2002, 271:143-164.

17. Drysdale M, Bourgogne A, Koehler TM: Transcriptional analysis of the Bacillus anthracis capsule regulators. J Bacteriol 2005, 187(15):5108-5114.

18. Mogensen EG, Janbon G, Chaloupka J, Steegborn C, Fu MS, Moyrand F, Klengel T, Pearson DS, Geeves MA, Buck J, et al: Cryptococcus neoformans senses $\mathrm{CO}_{2}$ through the carbonic anhydrase Can2 and the adenylyl cyclase Cac1. Eukaryot Cell 2006, 5(1):103-111.

19. Yang J, Hart E, Tauschek M, Price GD, Hartland EL, Strugnell RA, RobinsBrowne RM: Bicarbonate-mediated transcriptional activation of divergent operons by the virulence regulatory protein, RegA, from Citrobacter rodentium. Mol Microbiol 2008, 68(2):314-327.

20. Hoffmaster AR, Koehler TM: The anthrax toxin activator gene atxA is associated with $\mathrm{CO}_{2}$-enhanced non-toxin gene expression in Bacillus anthracis. Infect Immun 1997, 65(8):3091-3099.

21. Hondorp ER, Mclver KS: The Mga virulence regulon: infection where the grass is greener. Mol Microbiol 2007, 66(5):1056-1065.

22. Day AM, Cove JH, Phillips-Jones MK: Cytolysin gene expression in Enterococcus faecalis is regulated in response to aerobiosis conditions. Mol Genet Genomics 2003, 269(1):31-39.

23. Dai Z, Koehler TM: Regulation of anthrax toxin activator gene (atxA) expression in Bacillus anthracis: temperature, not $\mathrm{CO}_{2} /$ bicarbonate, affects AtxA synthesis. Infect Immun 1997, 65(7):2576-2582.

24. Schreiber S, Konradt M, Groll C, Scheid P, Hanauer G, Werling HO, Josenhans C, Suerbaum S: The spatial orientation of Helicobacter pylori in the gastric mucus. Proc Natl Acad Sci USA 2004, 101(14):5024-5029.

25. Wilson AC, Soyer M, Hoch JA, Perego M: The bicarbonate transporter is essential for Bacillus anthracis lethality. PLoS Pathog 2008, 4(11):e1000210.

26. Giard JC, Riboulet E, Verneuil N, Sanguinetti M, Auffray $Y$, Hartke A: Characterization of Ers, a PrfA-like regulator of Enterococcus faecalis. FEMS Immunol Med Microbiol 2006, 46(3):410-418.

27. Riboulet-Bisson E, Sanguinetti M, Budin-Verneuil A, Auffray $Y$, Hartke A Giard JC: Characterization of the Ers (PrfA-like) regulon of Enterococcus faecalis. Infect Immun 2008, 76(7):3064-3074

28. Hart E, Yang J, Tauschek M, Kelly M, Wakefield MJ, Frankel G, Hartland EL, Robins-Browne RM: RegA, an AraC-like protein, is a global transcriptional regulator that controls virulence gene expression in Citrobacter rodentium. Infect Immun 2008, 76(11):5247-5256.

29. Konturek SJ, Konturek PC, Pawlik T, Sliwowski Z, Ochmanski W, Hahn EG. Duodenal mucosal protection by bicarbonate secretion and its mechanisms. J Physiol Pharmacol 2004, 55(Suppl 2):5-17.

30. Kristich CJ, Wells CL, Dunny GM: A eukaryotic-type Ser/Thr kinase in Enterococcus faecalis mediates antimicrobial resistance and intestinal persistence. Proc Natl Acad Sci USA 2007, 104(9):3508-3513.

31. Singh KV, Nallapareddy SR, Nannini EC, Murray BE: Fsr-independent production of protease(s) may explain the lack of attenuation of an Enterococcus faecalis fsr mutant versus a gelE-sprE mutant in induction of endocarditis. Infect Immun 2005, 73(8):4888-4894.

32. Poyart C, Trieu-Cuot P: A broad-host-range mobilizable shuttle vector for the construction of transcriptional fusions to beta-galactosidase in gram-positive bacteria. FEMS Microbiol Lett 1997, 156(2):193-198.

33. Hancock LE, Shepard BD, Gilmore MS: Molecular analysis of the Enterococcus faecalis serotype 2 polysaccharide determinant. J Bacteriol 2003, 185(15):4393-4401.

34. Miller JH: Experiments in molecular genetics. Cold Spring Harbor Laboratory Press, US 1972

35. Sambrook J, Fritsch EF, Maniatis T: Molecular Cloning: a Laboratory Manual Cold Spring Harbor Laboratory Press, US 1989.

36. Murray BE, Singh KV, Ross RP, Heath JD, Dunny GM, Weinstock GM Generation of restriction map of Enterococcus faecalis OG1 and investigation of growth requirements and regions encoding biosynthetic function. J Bacteriol 1993, 175(16):5216-5223.

37. Bryan EM, Bae T, Kleerebezem M, Dunny GM: Improved vectors for nisincontrolled expression in gram-positive bacteria. Plasmid 2000 44(2):183-190

doi:10.1186/1471-2180-10-17

Cite this article as: Bourgogne et al:: Bicarbonate enhances expression of the endocarditis and biofilm associated pilus locus, ebpR-ebpABC, in Enterococcus faecalis. BMC Microbiology 2010 10:17.

\section{Submit your next manuscript to BioMed Central and take full advantage of:}

- Convenient online submission

- Thorough peer review

- No space constraints or color figure charges

- Immediate publication on acceptance

- Inclusion in PubMed, CAS, Scopus and Google Scholar

- Research which is freely available for redistribution

Submit your manuscript at www biomedcentral.com/submit 